\title{
The impact of method choice on the risk of contraceptive discontinuation: Egypt 2014
}

\author{
Mona Khalifa, Wafaa Abdel Aziz Hussein and Soha Metwally \\ Department of Biostatistics and Demography, Cairo University, Giza, Egypt
}

\begin{abstract}
Purpose - In Egypt, the IUD is the most common contraceptive method since 1988 and has remained so despite a recent drop in its share from $59.9 \%$ in 2008 to $51.5 \%$ in 2014 in favour of hormonal methods, which increased from $19.7 \%$ for pills and $12.3 \%$ for injectables in 2008 to $27.4 \%$ and $14.5 \%$ in 2014 according to 2014 Egypt demographic and health survey (EDHS). The recent shift away from intrauterine contraceptive device (IUDs) to hormonal methods have contributed to increased discontinuation. This paper aims to answer three questions: To what extent does the method type influence the hazard of contraceptive discontinuation in Egypt? Is the interaction between method type and duration of use a predictor of the probability of discontinuation after controlling other variables? What are the other important background variables that affect the hazard of contraceptive discontinuation?
\end{abstract}

Design/methodology/approach - Using data from EDHS2014, separate multilevel discrete-time proportional hazard models for events of interest (abandoned use while in need, switched to another method in the month following discontinuation and method failure) were built.

Findings - Only IUD users are significantly less likely to abandon use while in need and to experience method failure and a reduced risk of switching. During the first 6-10months of use, all types of discontinuation can be significantly reduced for all three methods. Demographic variables do not significantly affect abandonment but strongly affect switching and significantly affect failure. Socio-economic variables do not significantly affect abandonment and switching. Exposure to media has a significant effect on abandonment but not on switching. Community contraceptive prevalence rate strongly affects switching.

Originality/value - Results confirm that the counselling should be more intense during the first year of method use and should pay special attention to women who are 25 years old and above and those who have two or more children. Also, media campaigns are important and especially those addressing the issue of abandoning while in need.

Keywords Egypt, Discontinuation, Family planning, Multilevel discrete-time hazard

Paper type Research paper

\section{Background}

Contraceptive discontinuation has become a subject of increasing interest, as it is an important determinant of contraceptive prevalence and unwanted fertility (Steele and Curtis, 2003) and, as it may be associated with the quality of family planning programmes (Jain, 1989). This has led to the suggestion made by several studies that family planning

(C) Mona Khalifa, Wafaa Abdel Aziz Hussein and Soha Metwally. Published in Journal of Humanities and Applied Social Sciences. Published by Emerald Publishing Limited. This article is published under the Creative Commons Attribution (CC BY 4.0) licence. Anyone may reproduce, distribute, translate and create derivative works of this article (for both commercial and non-commercial purposes), subject to full attribution to the original publication and authors. The full terms of this licence maybe seen at http://creativecommons.org/licences/by/4.0/legalcode

The authors have no conflicts of interest to declare. 
JHASS
4,1

programmes can achieve better health and demographic results when they not only aim at recruiting new clients but also provide quality services to ensure that acceptors achieve their satisfaction and continue to use their chosen methods (Blanc et al., 2002; El-Tawila, 1995).

Acceptors may discontinue by abandoning use while they still want to avoid pregnancy or switch to another method. Others may discontinue because of a method of failure when they become pregnant while using a contraceptive. A recent study reported that "nonuse of contraception accounted for about two-thirds of unintended recent births in 36 countries, while contraceptive discontinuation accounted for the remaining one-third" (Jain and Winfrey, 2017). The same study reports that the contribution of contraceptive discontinuation to unintended births in Egypt in 2014 reached $66.4 \%$ while nonuse of contraception accounted for the remaining $33.6 \%$ of unintended recent births. These results make the determinants of contraceptive discontinuation among acceptors an issue of important programmatic implications.

Studies of contraceptive discontinuation have consistently shown that contraceptive discontinuation rates and the reasons for discontinuation vary substantially by the method type which was also found to be the most important determining factor (Ali and Cleland, 1995; Ferguson, 1992; Steele et al., 1996 cited in Bradley et al., 2009, p. 2; Castle and Askew, 2015). After examining contraceptive discontinuation in six developing countries, Curtis and Blanc (1997) suggested that method characteristics affect women's choice of a method and also affects discontinuation rates among users of a particular method. Steele and Curtis (2003) found that method choice is endogenous to contraceptive abandonment and method switching but not to method failure. A comparative study of the determinants of discontinuation in eight countries including data from Egypt demographic and health survey 2005 showed that in Egypt abandonment while in need, method switching and failure were strongly associated with the contraceptive method chosen after controlling for other factors (Bradley et al., 2009). In addition, the risk of discontinuing use was found to be related to the duration of use as women become more experienced in using a specific method. This is especially true of some modern, reversible methods because it may take some time before a woman is fully familiar with their use (Steele $e$ t al., 1996).

In Egypt, the IUD is the most common contraceptive method since 1988 and has remained so despite a recent drop in its share from $59.9 \%$ in 2008 to $51.5 \%$ in 2014 in favour of hormonal methods, which increased from $19.7 \%$ for pills and $12.3 \%$ for injectables in 2008 to 27.4 and $14.5 \%$ in 2014, respectively (Ministry of Health and Population [Egypt], ElZanaty and Associates [Egypt] and ICF International, 2015a). Higher rates of discontinuation in Egypt (within 12 months of use) were found among the users of pills $(41.8 \%)$, followed by injectable users $(37.9 \%)$ and $(14.3 \%)$ among the users of intrauterine contraceptive device (IUDs) (Ministry of Health and Population [Egypt], El-Zanaty and Associates [Egypt] and ICF International, 2015a). After using a contraceptive for two years $66 \%$ of pill users, $56 \%$, of injectable users and $37 \%$ of IUD users stopped using the method. After the third year $78 \%$ of pill users, about $70 \%$ of injectable users and $54 \%$ of IUD users had discontinued use (Khalifa et al., 2017). Changes in the contraceptive method mix - in favour of hormonal methods - were found responsible for $65.1 \%$ of the recent changes in the overall discontinuation rate which increased from $26.1 \%$ in 2008 to $30.3 \%$ in 2014 (Khalifa et al., 2020a). If this trend continues, increases in the discontinuation rate are expected.

The total fertility rate (TFR) in Egypt has dropped during the period 1988-2008 from 4.4 to 3 children per woman, and the contraceptive prevalence rate (CPR) has increased from $38 \%$ to about $60 \%$. However, fertility rose during the six-year period reported by the last two EDHS of 2008 and 2014, from its lowest level of 3.0 children per woman to 3.5 and the national goal of achieving a TFR of 2.1 by 2017 has not been achieved (National Population 
Council, 2015). TFR would have been only 2.8 if discontinuation due to method failure and method/service-related reasons were eliminated (Khalifa et al., 2020b). This indicates that discontinuation due to method failure and method/service-related reasons contributed to an increase in fertility by almost $20 \%$ in Egypt 2014.

This recent increase in fertility was accompanied by a slight decline in (CPR) from $60.3 \%$ to $58.5 \%$ in 2014 . Among the $41.5 \%$ of Egyptian non-users, $43.1 \%$ have never used any contraceptive method and $32.4 \%$ do not intend to use contraceptives in the future (ICF, 2019). The contraceptive discontinuation rate (percentage of contraceptive users who discontinue within 12 months of use) rose from its lowest ever level of $25.9 \%$ in 2008 to $30.1 \%$ the majority of which $(18.3 \%)$ was due to reasons other than reduced need (Ministry of Health and Population [Egypt], El-Zanaty and Associates [Egypt] and ICF International, 2015a). Unmet need, which is the proportion of married women who do not want to become pregnant but are not using family planning, remains high. It has increased from its lowest level of $11.6 \%$ in 2008 to $12.6 \%$ in 2014 implying a high level of unintended births. These changes imply a rise in the number of unintended births.

In addition to the method type, women's demographic and socioeconomic characteristics are determinants of discontinuation rates. Analysis of EDHS 2014 indicated that Egyptian women under age 25 and those with one living child have the highest contraceptive discontinuation rates $(35 \%)$ and $(42.6 \%)$, respectively. Rural women have high discontinuation rates (32.8\%) especially in rural Upper Egypt (37.7\%). Contraceptive discontinuation rates are also high among women with less than primary education $(33.1 \%)$ and those belonging to the poor wealth index category (33.6\%) (Khalifa et al., 2017). The strong policy and programme implications which these differentials imply can be more useful when presented for each category of discontinuation separately. Also, to determine the relationship between the type of discontinuation (abandoning use while in needswitching - failure of method) and the contraceptive method used, all of the other covariates need to be controlled.

This research attempts to answer three questions:

Q1. To what extent does the method type influence the hazard of contraceptive discontinuation in Egypt?

Q2. Is the interaction between method type and duration of use a predictor of the probability of discontinuation after controlling other variables?

Q3. What are the other important background variables that affect the hazard of contraceptive discontinuation?

\section{Data and methodology}

\subsection{Data}

The analysis is based on data from EDHS 2014. The EDHS 2014 involved a multi-stage sample design. EDHS sampling strategy involves selecting households from clusters (small geographical areas) and interviewing all eligible women in those households (Ministry of Health and Population [Egypt], El-Zanaty and Associates [Egypt] and ICF International, 2015a). Women residing in the same cluster area may share characteristics associated with the outcome of interest that were not captured in the models (Bradley et al., 2009).

The unit of the analysis is the most recent segment of contraceptive use for each married [1] woman who used a reversible contraceptive method during the period of observation (3-59 months) before the survey. The segment of use is defined as a continuous 
JHASS

4,1

period of use/non-use of a contraceptive method (in months). The study excludes the first three months prior to the interview to prevent bias, where the woman may be pregnant and not aware of this condition.

Durations of use more than 36 months were censored (treated as non-discontinuations), for women who did not experience any discontinuation during the study period and we use the recent right-censored segment of use. Three discontinuation models are considered in the analysis:

(1) abandoned use while in need;

(2) switched to another method; and

(3) method failure.

No longer in need is used as the reference group along with right-censored observations.

According to the aforementioned restriction, we have four cases:

(1) Left censored segments: They were excluded from the analysis because the date of initiation of use is unknown.

(2) Right censored segment: If there is no recent segment of use that ended with discontinuation for a woman during the study period, then this right-censored segment will be included in the analysis.

(3) A segment of use that ends with an event of interest (abandoned use while in needswitched to another method in following the month from discontinuation- method failure) will be included separately in the analysis.

(4) A segment of use that has ended with discontinuation for (the desire to have a child - no need for use) will be included as censored segments to join the right-censored segments.

Consequently, only one segment of use is considered for each woman, whether it ended with discontinuation or continued use during the study period 3-59 months before the survey. The sample size is 10,463 segments which contain, namely, $11.3 \%$ abandoned use while in need, $7 \%$ switched to another method, $6.5 \%$ discontinued due to method failure and $75.2 \%$ continued to use or no longer in need (Table 1 ).

2.1.1 Independent variables. The characteristics of women used in the analysis are those recorded at the time - in century months $(\mathrm{CMC})$ - for discontinuation and pregnancy. The background characteristics of women are divided into three groups as described in Figure 1. The first includes the individuals' characteristics age at the intuition of use, number of living children, level of education, wealth index, work status and mass media exposure. The value of mass media exposure can range from 0 (no media exposure about family planning) to 3 (heard about family planning from television, radio and newspaper/magazine in the past few months). As the value increases, the higher is the woman's exposure to mass media about family planning. The value is included as a continuous variable in the models. Community contraceptive prevalence (at the district level). The second group includes the variables of method; duration of use and the interaction between method type and duration of use. The analysis is focussed on the three most commonly used contraceptive methods (pills - injectables - IUDs), which account for 93\% of the method mix in 2014 . The duration of use of the last (the most recent) episode of use is treated as an independent variable. The third group includes variables at the community level; place of residence and community contraceptive prevalence (at the district level) is calculated as the percentage of women in a cluster, excluding the index woman, using contraception (Bradley et al., 2009). These 


\begin{tabular}{|c|c|c|c|c|c|c|}
\hline Characteristics & $\begin{array}{l}\text { Right censored and } \\
\text { reduced need }\end{array}$ & $\begin{array}{l}\text { Abandoning use } \\
\text { while in need }\end{array}$ & $\begin{array}{l}\text { Switched to } \\
\text { another method }\end{array}$ & $\begin{array}{l}\text { Method } \\
\text { failure }\end{array}$ & Total & $\begin{array}{l}\text { Impact of } \\
\text { method choice }\end{array}$ \\
\hline $\begin{array}{l}\text { Age at intuition of use } \\
15-24 \\
25-34 \\
35-49\end{array}$ & $\begin{array}{l}33.4 \\
51.1 \\
15.8\end{array}$ & $\begin{array}{l}33.2 \\
53.2 \\
13.6\end{array}$ & $\begin{array}{l}22.3 \\
57 \\
20.8\end{array}$ & $\begin{array}{r}30.6 \\
59.6 \\
9.8\end{array}$ & $\begin{array}{l}32.4 \\
52.3 \\
15.5\end{array}$ & \\
\hline $\begin{array}{l}\text { Number of living children } \\
\text { One child at most } \\
\text { Two } \\
\text { Three } \\
\text { Four or more }\end{array}$ & $\begin{array}{l}22.4 \\
30.8 \\
25.3 \\
21.5\end{array}$ & $\begin{array}{l}19.2 \\
31.2 \\
25.3 \\
24.4\end{array}$ & $\begin{array}{l}12.8 \\
30.7 \\
31 \\
25.6\end{array}$ & $\begin{array}{l}13.6 \\
36.9 \\
23.6 \\
26\end{array}$ & $\begin{array}{l}20.8 \\
31.3 \\
25.6 \\
22.4\end{array}$ & \\
\hline $\begin{array}{l}\text { Place of residence } \\
\text { Urban governorates } \\
\text { Urban lower Egypt } \\
\text { Rural lower Egypt } \\
\text { Rural upper Egypt } \\
\text { Urban upper Egypt } \\
\text { Frontiers governorate }\end{array}$ & $\begin{array}{l}11.4 \\
10.5 \\
42 \\
10.8 \\
24.3 \\
0.9\end{array}$ & $\begin{array}{r}8.9 \\
7.3 \\
34.9 \\
9.2 \\
38.9 \\
0.8\end{array}$ & $\begin{array}{r}10.1 \\
11.2 \\
47.9 \\
9.5 \\
20.4 \\
0.9\end{array}$ & $\begin{array}{r}11.9 \\
10.5 \\
38.2 \\
11.9 \\
26.6 \\
0.9\end{array}$ & $\begin{array}{r}11.1 \\
10.2 \\
41.4 \\
10.6 \\
25.9 \\
0.9\end{array}$ & \\
\hline $\begin{array}{l}\text { Level of education } \\
\text { No education } \\
\text { Primary } \\
\text { Secondary } \\
\text { University or more }\end{array}$ & $\begin{array}{r}18.5 \\
8.6 \\
56.5 \\
16.4\end{array}$ & $\begin{array}{c}23 \\
9.7 \\
55.3 \\
12\end{array}$ & $\begin{array}{l}14.4 \\
10 \\
62.8 \\
12.9\end{array}$ & $\begin{array}{l}15.3 \\
10.7 \\
56.6 \\
17.4\end{array}$ & $\begin{array}{r}18.5 \\
8.9 \\
56.8 \\
15.7\end{array}$ & \\
\hline $\begin{array}{l}\text { Wealth } \\
\text { Low } \\
\text { Middle } \\
\text { High }\end{array}$ & $\begin{array}{l}34.6 \\
25.2 \\
40.2\end{array}$ & $\begin{array}{l}45.3 \\
24.7 \\
30\end{array}$ & $\begin{array}{l}34.7 \\
27.7 \\
37.6\end{array}$ & $\begin{array}{l}37.2 \\
20.7 \\
42.2\end{array}$ & $\begin{array}{l}36 \\
25 \\
39\end{array}$ & \\
\hline $\begin{array}{l}\text { Worked in past } 12 \text { months } \\
\text { No } \\
\text { Yes }\end{array}$ & $\begin{array}{l}85.6 \\
14.4\end{array}$ & $\begin{array}{l}83.7 \\
16.3\end{array}$ & $\begin{array}{l}84.2 \\
15.9\end{array}$ & $\begin{array}{l}85.5 \\
14.5\end{array}$ & $\begin{array}{l}85.3 \\
14.7\end{array}$ & \\
\hline $\begin{array}{l}\text { Method type } \\
\text { Pills } \\
\text { Injectables } \\
\text { IUDs } \\
\text { Other methods }\end{array}$ & $\begin{array}{r}35.6 \\
15.2 \\
44.2 \\
5.1\end{array}$ & $\begin{array}{c}39.1 \\
29.2 \\
23.7 \\
8\end{array}$ & $\begin{array}{r}34.8 \\
19.7 \\
39.2 \\
6.4\end{array}$ & $\begin{array}{l}49.8 \\
14.4 \\
24.5 \\
11.3\end{array}$ & $\begin{array}{l}49.8 \\
14.4 \\
24.5 \\
11.3\end{array}$ & \\
\hline $\begin{array}{l}\text { Duration of use } \\
1-5 \\
6-10 \\
11-15 \\
16-20 \\
21-25 \\
26-30 \\
31-36 \\
\text { Total counts } \\
\text { Total row percentage }\end{array}$ & $\begin{array}{c}19.3 \\
13.2 \\
11.7 \\
10.7 \\
10 \\
7.8 \\
27.3 \\
7,866 \\
75.2\end{array}$ & $\begin{array}{r}32.5 \\
22.2 \\
15.1 \\
11.1 \\
9.8 \\
4.3 \\
5.1 \\
1,183 \\
11.3\end{array}$ & $\begin{array}{c}28.6 \\
26.2 \\
13.6 \\
10.4 \\
8 \\
6.1 \\
7.1 \\
730 \\
7\end{array}$ & $\begin{array}{c}30 \\
21 \\
19.8 \\
11.9 \\
8.4 \\
3.7 \\
5.2 \\
684 \\
6.5\end{array}$ & $\begin{array}{c}22.2 \\
15.7 \\
12.8 \\
10.8 \\
9.7 \\
7 \\
21.9 \\
10,463 \\
100.0\end{array}$ & $\begin{array}{r}\text { Table 1. } \\
\text { Per cent distribution } \\
\text { of characteristics of } \\
\text { women according to } \\
\text { discontinuation } \\
\text { status: Egypt 2014 }\end{array}$ \\
\hline
\end{tabular}

variables could be classified into time-variant and time-invariant. The former includes age at the intuition of use, number of living children, method type and duration of use. The latter group includes the level of education, wealth index, work status and mass media exposure and community contraceptive prevalence. 


\section{JHASS \\ 4,1}

44

Figure 1.

Theoretical framework for the factors impacting the contraceptive discontinuation

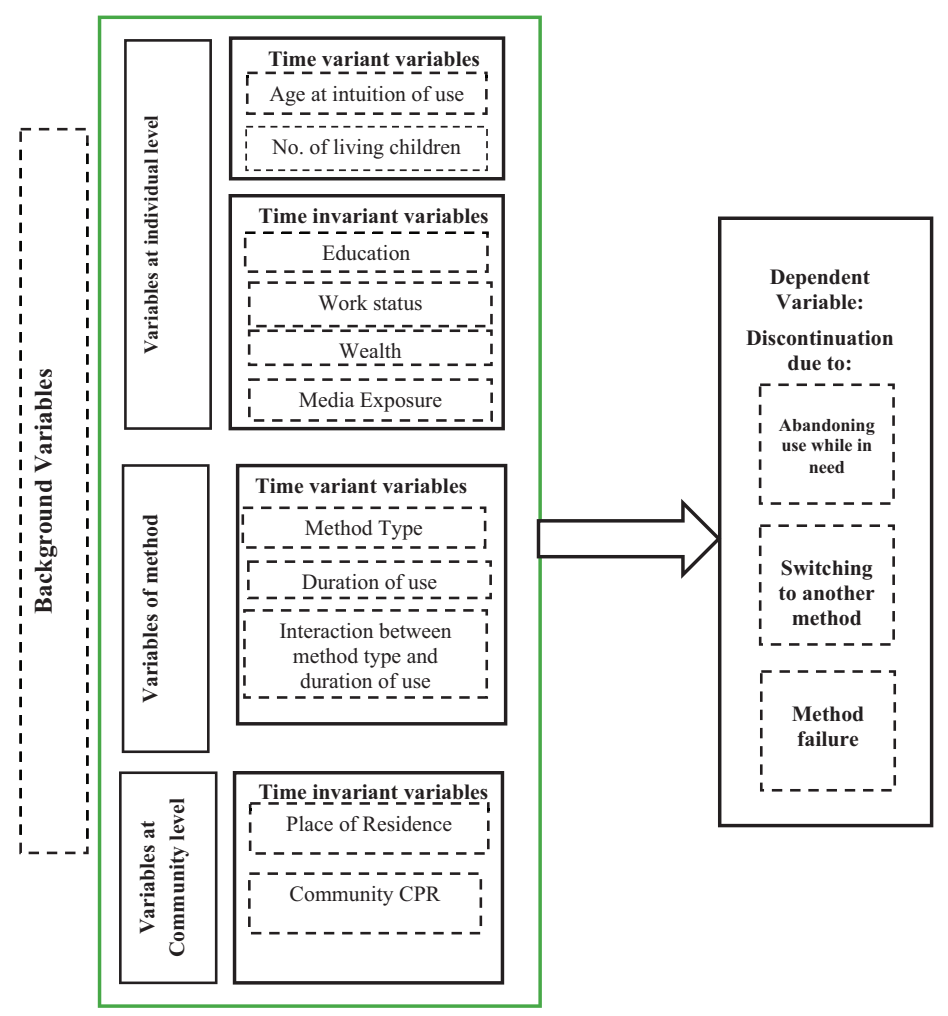

2.1.2 Data manipulations. The data needed to be restructured to be suitable for discrete-time analysis (person-the period file was created). However, the non-existence of the event of interest (discontinuation) at a specific time point (month) leads to increasing the difficulty of estimating the probability of discontinuation for this time point. This can be handled by expanding data into discrete time intervals. Therefore, the study period was divided into periods of 5 months to prevent the dropout of any period from the model due to lack of discontinuations during this interval. Each time period represents 5-month length except the final interval (it has six-month length).

For example, for individual $i$ who located in cluster $\mathrm{j}$ is recorded in intervals of time and $t_{i j}$ is the number of intervals for individual $i$ who located in cluster $\mathrm{j}$. Then, let $y_{t i j}$ be a binary variable of the event of interest:

$$
y_{t i j}= \begin{cases}1 & \text { if segment of use for individual } \mathrm{i} \text { in cluster } \mathrm{j} \text { ends in an event during interval } \mathrm{t} \\ 0 & \text { otherwise }\end{cases}
$$

So, $y_{t i j}$ will be 0 for time intervals regardless of whether their duration is censored for all segments of use, where $t=1, \ldots, t_{i j}-1$. Then, the value of the last observed interval $y_{t_{i j} i j}$ will be 1 for segments of use that end in an event during that time interval and 0 for those that are censored at $t_{i j}$. 
2.1.3 Dependent variables. The probability of a woman discontinuing a contraceptive method for the event of interest $r_{k}$ during a specific month, given that there is no discontinuation occurred to this woman before. $r_{k}$ denotes to the following statuses (abandoned use while in need, switched to another method in the month following discontinuation and method failure). It can be written as:

$$
h_{i j}(t)^{r_{k}}=\operatorname{pr}\left(y_{t i j}{ }^{r_{k}}=1 \mid y_{t^{\prime} i j^{r_{k}}}^{r}=0\right)
$$

where

$$
\begin{aligned}
& t^{\prime}<t \\
& \mathrm{j}=1, \ldots, \mathrm{M} \text { independent districts and district } \mathrm{j} \text { consisting of } \mathrm{i}=1, \ldots, n_{j} \text { observations } \\
& \text { (individuals). } \\
& r_{k} \text { where } \mathrm{k}=1,2,3 \\
& r_{1} \text { if in case of abandoned use while in need } \\
& r_{2} \text { if in case of switching to another method in the month following discontinuation. } \\
& r_{3} \text { if in case of method failure. }
\end{aligned}
$$

$$
y_{t i j}{ }^{r k}= \begin{cases}1 & \begin{array}{l}
\text { if segment of use for individual i in cluster } \mathrm{j} \text { ends in an event of interest } r_{k} \\
\text { during interval t }
\end{array} \\
0 & \text { otherwise }\end{cases}
$$

2.1.4 Data quality and limitations. There are several limitations, which are related to the retrospective nature of DHS calendar data that should be kept in mind when interpreting the results of this paper. Firstly, women who used a method were asked to specify the contraceptive method used and if more than one method were used during the month of observation, only the most effective one was recorded. In such instance a switching episode within the month-period is missed. Secondly, only one reason for continuation was collected. In reality, there are often multiple reasons for discontinuing a contraceptive method (Bradley et al., 2009). Hereby a comprehensive analysis of reasons of discontinuation is unexploited. Finally, the segments of use that started before the beginning of the calendar (left-censored) were excluded while the right-censored segments were included in almost all studies that meant to analyze the determinants of contraceptive discontinuation (Curtis and Hammerslough, 1995; Bradley et al., 2009).

\subsection{Methodology}

The duration of contraceptive discontinuation is measured in discrete time units (months units), and there will be the possibility of multiple ties (events are tied when two or more individuals experience an event at the same time) (Arifin, 2003). So, continuous survival analysis is not the appropriate method in this case. The study will use Discrete-time hazard model because it allows for tied observations.

The Discrete-time hazard models use a discrete version of the hazard function. Binomial regression models, with a logit, probit or complementary log-log link function can be used to model the probability that the event occurred at a specified discrete time point conditional on the fact that it had not yet occurred (Rabe-Hesketh and Skrondal, 2012 cited in Austin, 2017).

To estimate the hazard risk of discontinuing by women characteristics, this study implements three separate Multilevel discrete-time proportional hazard models for events of 
JHASS 4,1

interest (abandoned use while in need, switched to another method in the month following discontinuation and method failure). In each model, the reference category is women who did not stop (right censored) and those no longer in need (reduced need).

Multilevel models are needed because with grouped data the observations in the same group are generally more similar than the observations from different groups, which violates the assumption of independence of all observations (Hox, 1995). Discrete-time survival models can easily incorporate the multilevel structure of the data (Austin, 2017).

The study measures the variation at both the individual and sampling cluster levels using multilevel discrete-time proportional hazard models. We do not need to include the episode as a level of analysis in our multilevel models, as we restricted our analysis to only one episode of contraceptive use per woman, (Bradley et al., 2009).

In the following, we present the general formula of the two-level mixed logistic regression model, then the formula that is applied in the present study which derives from the general formula.

Firstly, the general formula of two-level mixed-effects logistic regression model for binary and binomial responses can be written as: $\operatorname{pr}\left(y_{i j}=1 \mid x_{i j}, u_{j}\right)=H\left(x_{i j} \beta+z_{i j} u_{j}\right)$ (StataCorp, 2015).

Where

$\mathrm{H}($.$) : the logistic cumulative distribution function$

$\mathrm{j}=1, \ldots, \mathrm{M}$ independent clusters and cluster $j$ consisting of $i=1, \ldots, n_{j}$ observations.

$y_{i j}$ : binary variable

$x_{i j}$ : the covariates for the fixed effects ( $1 \times \mathrm{p}$ row vectors).

$B:$ Regression coefficients (fixed effects).

$z_{i j}$ : (The $1 \times \mathrm{q}$ vector) are the covariates corresponding to the random effects and can be used to represent both random intercepts and random coefficients. In a random-intercept model, $z_{i j}$ is simply the scalar 1 .

$u_{j}$ : (Random effects) are $\mathrm{M}$ realizations from a multivariate normal distribution with mean 0 and $\mathrm{q} \times \mathrm{q}$ variance matrix $\Sigma$.

The probability of a success $\operatorname{pr}\left(y_{i j}=1\right)$ can be expressed by $H(v)=\frac{e^{v}}{1+e^{v}}$.

The hazard function (also known as the transition rate or failure rate), which in discretetime is defined as $p_{t i j}=\operatorname{pr}\left(y_{t i j}=1 \mid y_{t i j}=0\right.$ for $\left.t^{\prime}<\mathrm{t}\right)$ (Steele, 2011). That is, the conditional probability that an event occurs in interval $t$ of episode $i$ of individual $j$ given that the event has not yet occurred in that episode.

Secondly, the case of two-level discrete time hazard models (at both the individual and cluster levels) of events of interest $r_{k}$, which $r_{k}$ denotes to (abandoned use while in need, switched to another method in the month following discontinuation and method failure), can be written as:

$$
h_{i j}(t)^{r_{k}}=\operatorname{pr}\left(y_{t i j}{ }^{r_{k}}=1 \mid y_{t i j}{ }^{r_{k}}=0\right)=H\left(x_{t i j} \beta^{r_{k}}+\alpha_{t}^{r_{k}}+u_{j}^{r_{k}}\right)
$$

\section{Where}

$t^{\prime}<t r_{k}$ where $\mathrm{k}=1,2,3$

$r_{1}$ if in case of abandoned use while in need

$r_{2}$ if in case of switched to another method in the month following discontinuation.

$r_{3}$ if in case of method failure.

$\mathrm{j}=1, \ldots, \mathrm{M}$ districts and district $\mathrm{j}$ consisting of $\mathrm{i}=1, \ldots, n_{j}$ observations (individuals).

$h_{i j}(t)^{r_{k}}$ is hazard of contraceptive discontinuation of event of interest $r_{k}$ at time interval $t$.

$y_{t i j}{ }^{{ }^{\prime}}$ is binary variable of event of interest $r_{k}$.

$\mathrm{H}($.) is the logistic cumulative distribution function. 
$x_{t i j}$ are covariates which might be time-varying or defined at individual level.

$\alpha_{t}^{\gamma_{k}}$ is called the logit of the baseline hazard function. $\alpha_{t}^{r_{k}}=\alpha_{1}{ }^{r_{k}} D_{1}+\alpha_{2}{ }^{r_{k}} D_{2}+\ldots+$ $\alpha_{q}{ }^{r_{k}} D_{q}$. where $\mathrm{D}_{1}, \mathrm{D}_{2}, \ldots, \mathrm{Dq}$ are dummies for time intervals $\mathrm{t}=1,2, \ldots, \mathrm{q}$ and $\mathrm{q}=6$.

We are in the case of the random-intercept model and the random effects at the district level and we used melogit stata command to implement Two-level discrete-time hazard model. The test of odds proportionality (the effects of different independent variables do not change over time) was implemented by testing the interaction between the duration of use dummy variables and the independent variables included in the model. A few violations of this assumption were found for the independent variable, so that these interactions will not be included in the model, except for interaction between the method type and the duration of use. Usually previous studies they include only the interaction between method type and duration of use (El-Tawila, 1995) based on the fact that the discontinuation by method differs by duration.

\section{Results}

\subsection{Determinants of abandoning use while in need}

Stopping the use of a contraceptive while women still wish to avoid pregnancy is a main constrain that faces their progress to achieving their family size targets. The "abandoned use while in need" status took place for $7.3 \%$ and $6.5 \%$ of the user segments at the time of the 2008 and 2014 surveys, respectively. These rates amount to $28 \%$ and $21.4 \%$ of the 12 month contraceptive discontinuation rates, respectively (Khalifa et al., 2017). The highest discontinuation rate for abandoned while in need $(12.1 \%)$ was reported for injectable users (Khalifa et al., 2017). Focus group discussion conducted in 2011 concluded that "side effects" is the main reason for discontinuation among injectable users (Social Research Center, 2011).

Table 2 displays the determinants of abandoning use while in need. The analysis shows no significant effect of the age of women, number of living children, place of residence, level of education, woman's work and wealth index related to contraceptive discontinuation while still in need. Exposure to mass media is significantly associated with decreases in the odds of abandonment while in need. The more types of media exposure the less risk of abandonment by $28 \%$.

The results indicate that only IUD users are significantly less likely to abandon use while in need (almost 0.28 chance) compared to users of reversible methods other than the three most common methods. The risk of discontinuation while in need of all three methods is higher during 6-10 months compared with the time interval less than 6 months by 1.25 times.

The interaction between the method type and period of use is the most powerful significant predictor of the probability of abandoning use while in need. The odds of abandoning use while in need takes a decreasing trend across time for all three methods if the use interval 21-25 month is excluded. There are obvious reductions in the chances of discontinuation until the last period of use ( 3 years and above). This confirms that the longer the duration of use the less is the probability of abandoning use while in need.

Figure 2 presents the distribution of characteristics of women who abandoned use while in need of the significant independent variables based on the results of Table 2.

\subsection{Determinants of switching to another method}

Contraceptive switching has been studied/examined as an essential/a potential indicator of family planning service quality, though whether high rates of switching associate to strong or weak service provision has been debated in the literature (Bradley et al., 2009). The 
JHASS

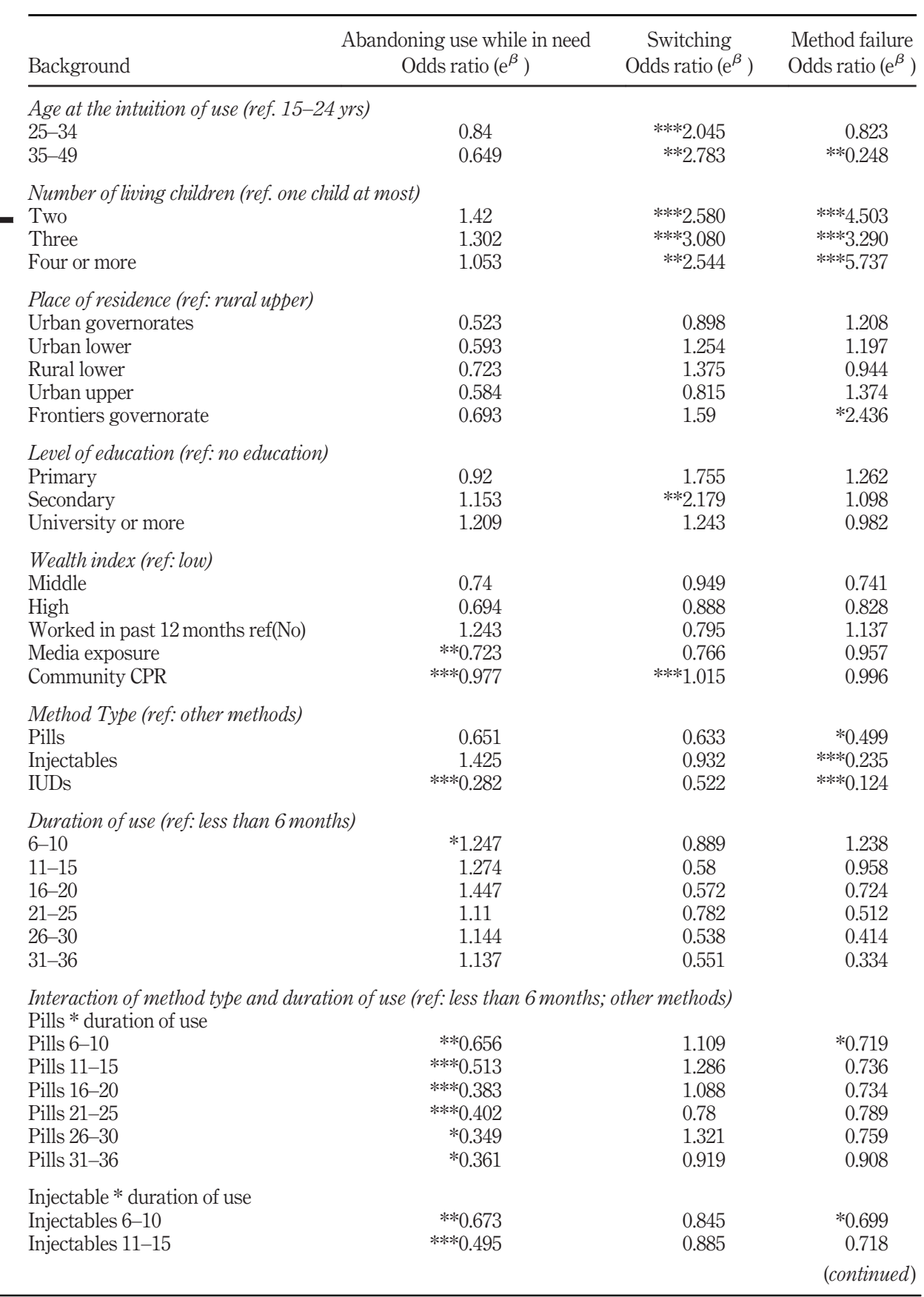

Table 2.

Determinants of hazard risk of discontinuation in case of abandoning use while in need, switching and method failure: Egypt 2014 


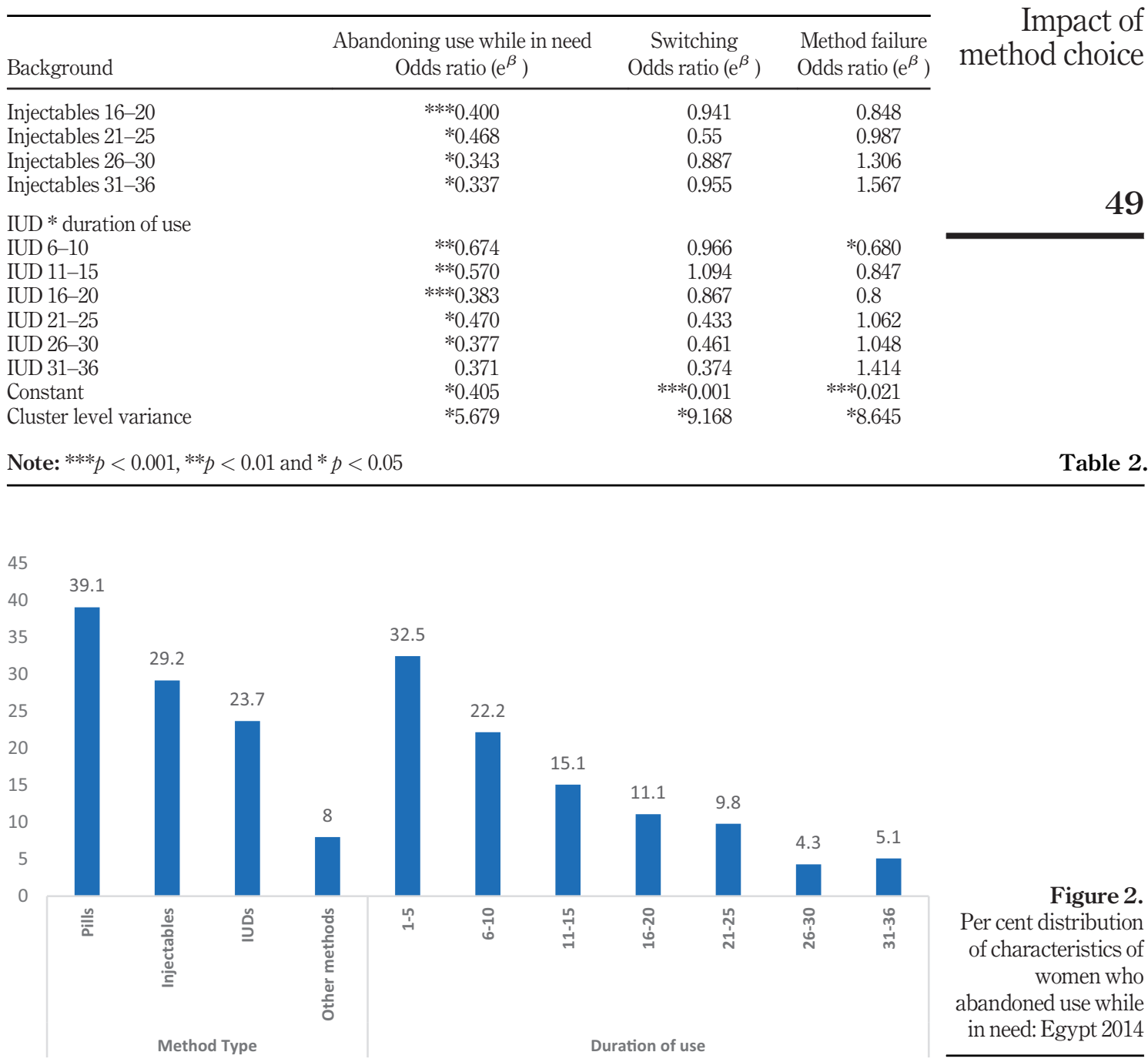

contraceptive switching rate which is the percentage of women who switch to a new method within one month of stopping the old one is estimated at $7.8 \%$ in both 2008 and 2014 (Khalifa et al., 2017). This is $29.9 \%$ of the total discontinuation in 2008 and $25.7 \%$ in 2014, the highest switching rate $(11 \%)$ being for injectable users.

The hazard of switching is most strongly associated with the age of women at the beginning of use, a number of living children, women's education and CPR at the community level as presented in Table 2 . The higher the age of a woman, the more likely she is to switch to another method. Women in the age group 25-34 have double the chances to switch and this probability increases to 2.8 times among the women in the age group 35-49 compared with the reference age group. 
JHASS 4,1

50

Women with 3 children have the highest chances of switching compared to women with at most one child. The higher the education, the higher the probability to switch although significant only among women with secondary education and is 2.2 times that of the uneducated women.

On the other hand, the wealth index, place of residence, work status in the past year, media exposure are not significantly related to switching to another method. Also, the analysis shows that the method type and the interaction variable between method type and duration of use are not significantly related to switching to another method.

Figure 3 presents the distribution of characteristics of women who switched to another method by the significant independent variables based on the results of Table 2.

\subsection{Determinants of the risk of method failure}

The contraceptive failure rate within 12 months after beginning use was estimated at $2.9 \%$ in 2008 and went up to $4.3 \%$ in 2014 (Ministry of Health and Population [Egypt], El-Zanaty and Associates [Egypt] and ICF International, 2015a). As a reason for discontinuation, failure formed $11.1 \%$ of the overall discontinuation rate in 2008 and increased to $14.2 \%$ in 2014. The highest failure rate $(7.7 \%$ ) was found for pill users (Khalifa et al., 2017).

Table 2 shows that women's level of education, place of residence, wealth index, work status and the duration of contraceptive use have no effect on discontinuing due to method failure. On the other hand, women's age at the beginning of use, the number of living children and the method type are the variables that have a significant effect on method failure. Older women are less likely to experience method failure (women 35-49 years of age have about 0.25 chances to stop compared to the younger age group). Women with four or more children have the highest odds to discontinue. They are 6 times more likely compared to women with one child at most. This probability is 4.5 times among women with two children and is lowest among women with three children which is 3.3 times only. Users in Frontiers governorates are 2.4 times likely to experience method failure compared with users in rural Upper Egypt.

The type of used method strongly influences the risk of discontinuation due to method failure. The results show that the risk of method failure among IUD users is substantially lower than those for the other two common methods. IUD users have only 0.12 of the chance of method failure compared with women using methods other than the three common contraceptives. This chance is 0.5 times for pills and 0.24 times for injectables.

Figure 3.

Per cent distribution of characteristics of women who switched to another method: Egypt 2014

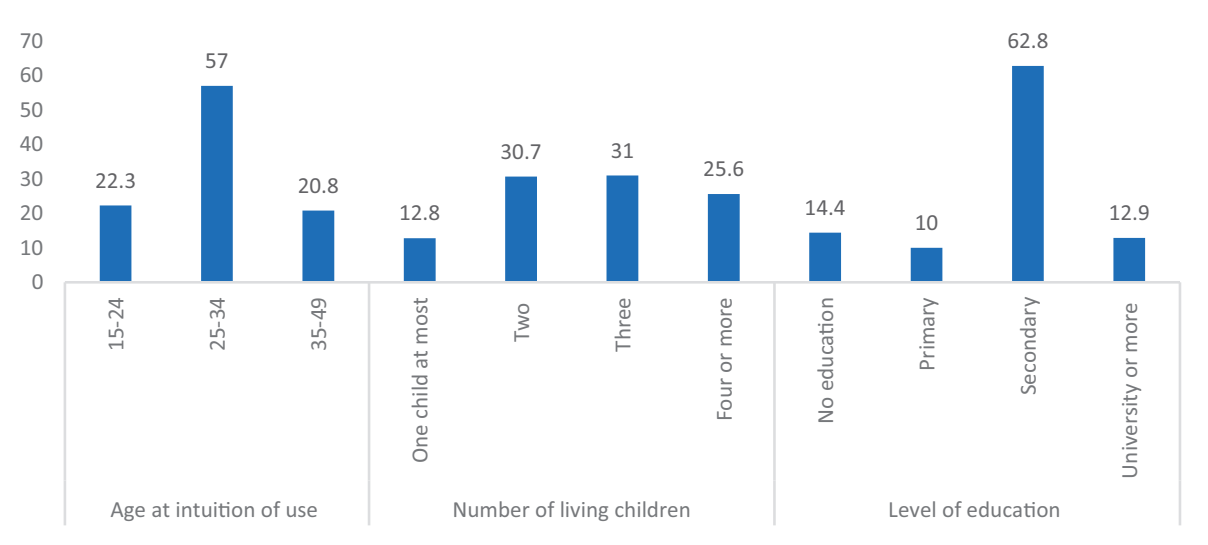


The interaction between "duration of use and type of method" has no significant effect on the risk of method failure, except during the period of 6-10 months among users of all three method types. They have the same chance to discontinue due method failure which is 0.7 times compared to that among users of methods other than the main three methods.

Cluster level variation has strong and significant impact on the likelihood of method/ service-related discontinuation (abandoning use while in need, switching and method failure). This means that the variables included in our three models do not captured the cluster-level variance. The highest variance was observed in the models of switching and method failure.

Figure 4 presents the distribution of characteristics of women who have method failure by the significant independent variables based on the results of Table 2.

Table 3 presents the trend in odds ratios for the three models. Results based on data of the 2005 EDHS using a slightly different coding of the variables (Bradley et al., 2009) found the odds ratios for all three methods in all three types of discontinuation models to be statistically significant and consistently lower than the odds reported in this study. While our results confirm that the three methods lower the chance of contraceptive failure significantly (being most effective among IUD users and least among pill users), it also confirms that the IUD became the only method that still has a significant influence on the risk of abandonment while in need. The risk of switching although not significant has

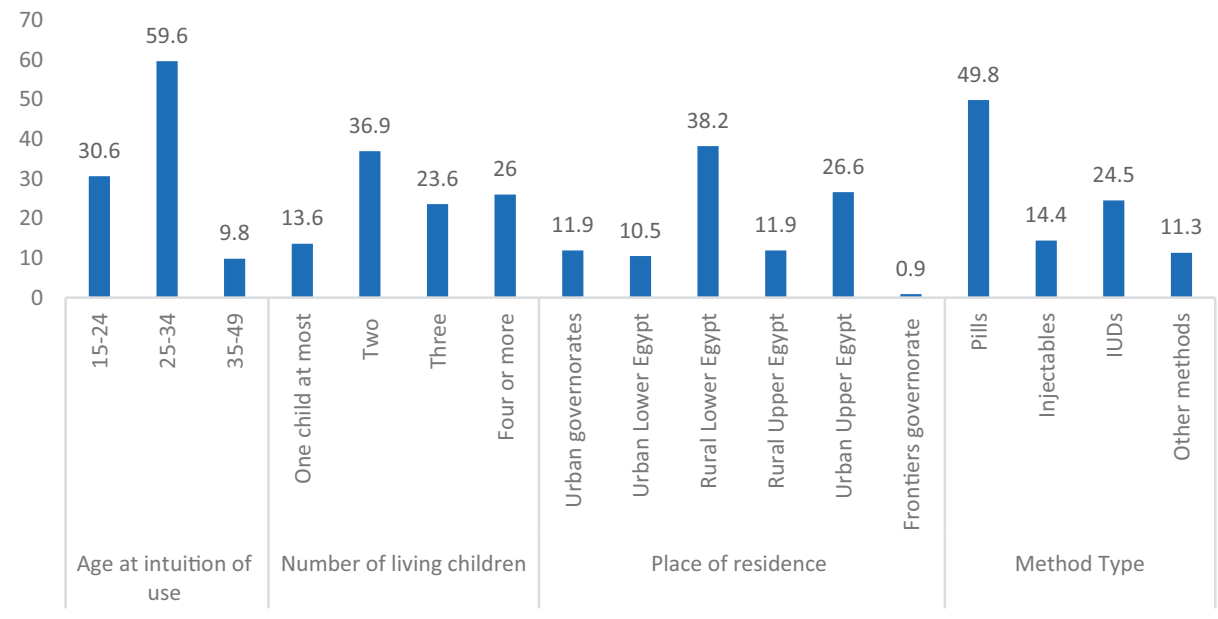

Figure 4 .

Per cent distribution of characteristics of women who have method failure method: Egypt 2014

\begin{tabular}{|c|c|c|c|c|c|c|}
\hline \multirow[b]{3}{*}{$\begin{array}{l}\text { Method of } \\
\text { contraceptive }\end{array}$} & \multicolumn{2}{|c|}{ Abandoning use while in need } & \multicolumn{2}{|c|}{ Switching } & \multicolumn{2}{|c|}{ Method failure } \\
\hline & DHS2014 $^{\mathrm{a}}$ & DHS2005 & DHS2014 & DHS2005 & DHS2014 & DHS2005 \\
\hline & $\begin{array}{l}\text { Ref: other } \\
\text { methods }\end{array}$ & $\begin{array}{l}\text { Ref: traditional } \\
\text { methods }\end{array}$ & $\begin{array}{l}\text { Ref: other } \\
\text { methods }\end{array}$ & $\begin{array}{l}\text { Ref: traditional } \\
\text { methods }\end{array}$ & $\begin{array}{l}\text { Ref: other } \\
\text { methods }\end{array}$ & $\begin{array}{l}\text { Ref: traditional } \\
\text { methods }\end{array}$ \\
\hline Pills & 0.65 & $0.53 * *$ & 0.63 & $0.46 * *$ & $0.50 *$ & $0.40 * *$ \\
\hline Injectables & 1.43 & $0.80 *$ & 0.93 & $0.39 * *$ & $0.24 * * *$ & $0.07 * *$ \\
\hline IUD & $0.28 * * *$ & $0.17 * *$ & 0.52 & $0.06 * *$ & $0.12 * * *$ & $0.04 * *$ \\
\hline
\end{tabular}

Note: $* * * p<0.001, * * p<0.01$ and $* p<0.05$

Source: ${ }^{a}$ Calculated by the authors, ${ }^{b}$ Bradley et al. (2009)

Table 3.

Determinants of hazard risk of discontinuation in case of abandoning use while in need, switching method failure: Egypt 2005 and 2014 
$\underset{4,1}{\text { JHASS }}$

increased for all three methods. This indicates a great change in discontinuation behaviour during the period 2005-2014.

\section{Discussion and conclusion}

This current analysis investigated contraceptive discontinuation in Egypt, focussing on abandonment while in need, switching and failure among users of pills, injectables and IUDs. Although recent evaluations of the family planning programme are not available, the Egypt Population Strategic Plan suggests that the family planning programme effort has decreased. It acknowledges that one of the challenges faced by the programme following the 2011 revolution is the decline of resources. It states that:

This had a negative impact on the availability of family planning methods and the quality of services provided, which, in turn, contributed to the increase in unmet need, the decline in reliance on public sector service providers and the switching to less effective methods (National Population Council, 2015).

Therefore, we expect to see these challenges reflected as recent increases in discontinuation rates continue. This expectation is based on the results of other studies that have indicated a strong correlation between family planning efforts and contraceptive discontinuation particularly in - need discontinuation rates (Blanc et al., 2002). Although a recent increase in the all method discontinuation rate has occurred, this was not true for all methods and for all categories of discontinuation during the period 2008-2014. Although failure rates increased significantly, for all methods (pills from 6.0 to 7.7 , injectables from 0.9 to 1.4 and IUD from 0.9 to 1.2 ), abandonment while in need has significantly decreased (pills from 8.5 to 7.5 , injectables from 13.7 to 12.1 and IUD from 3.5 to 3.2). On the other hand, the "switched" rate significantly increased among the IUD users only, from $3.3 \%$ in 2008 to $4.6 \%$ in 2014 while it dropped for hormonal methods (pills from 9.5 to 8.3 and injectables from 11.5 to 11.0) (Khalifa et al., 2017). To examine the implication of these results regarding the assessment of the family planning programme other variables including the duration of use were controlled.

The use of pills had a statistically significant effect only on lowering the failure rates in comparison with the use of reversible methods other than the three common methods. Although not significant, the use of pills reduces the risk of abandonment while in need by about $35 \%$ and the risk of switching by about $37 \%$.

The risk of experiencing method failure among pill users increases as duration of use increases although it is only significant during the first 6-10 months of use reaching $28 \%$. Also, they are significantly less likely to abandon use while in need during all durations of use. The risk of abandoning use while in need is reduced by a value that ranges from a low level of $34.4 \%$ during the first $6-10$ months of use to its highest level of about $65 \%$ after the second year of use. Although not statistically significant the use of pills increases the risk of switching by a value that ranges between $8.8 \%$ during the period $16-20$ months to $32.1 \%$ after the second year of use. Although these results suggest a fairly positive behaviour, it may also reflect the need for pill choosers to receive better counselling regarding switching to more effective methods and the timing so as to reduce the time gap between stopping the pill and starting the new method. It is reported that only $34.4 \%$ of the current pill users obtain their method from public sector sources (Ministry of Health and Population [Egypt], El-Zanaty and Associates [Egypt] and ICF International, 2015b). The majority relies on pharmacies where counselling is totally unavailable. Research is needed to identify the reasons behind the frequent stopping of the method including cost, availability and 
accessibility of the pills (Ministry of Health and Population [Egypt], El-Zanaty and Associates [Egypt] and ICF International, 2015a).

Similar to pills, the use of injectables had a statistically significant effect only on lowering the failure rates in comparison with the use of reversible methods other than the three common methods. The use of injectables increase the risk of abandoning while in need by $43 \%$ and reduce the risk of switching by only $7 \%$. Also similar to pills, reducing the risk of failure among injectable users is only significant during the first 6-10 months of use by $30 \%$. It is clear that the use of injectables significantly lowers the risk of abandoning while in need during all periods of use. The reducing effect ranges from $32.7 \%$ during the first 6 10 months of use to $66.3 \%$ during the $31-36$ months of use. The use of injectables reduces the risk of switching to another method but the effect is not statistically significant during all periods of use. These results suggest that counselling injectable users is less than successful. The improvement is needed especially in the public sector service facilities where $83.1 \%$ of the injectable users get their method and information (Ministry of Health and Population [Egypt], El-Zanaty and Associates [Egypt] and ICF International, 2015a).

The IUD is found to be the only method that has a statistically significant effect on reducing the risk of abandoning use while in need. The chance of abandoning the use of the IUD is $72 \%$ lower than reversible methods other than the three common ones. It reduces the risk of switching by $48 \%$ and significantly lowers the risk of method failure by $88 \%$ compared to other methods. Against expectations, the discontinuation behaviour of IUD users does not indicate a drop in the quality of service provision in Egypt. The use of IUD significantly reduces the risk of method failure compared to reversible methods other than the three common methods by $32 \%$. It also significantly reduces the risk of abandoning while in need during the first 30 months of use by $32.6 \%$ to $62.3 \%$. The relationship between the risk of switching among IUD users and the duration of use is complicated. Although not statistically significant, the use of IUD has very little effect on reducing the risk of switching during the first 20 months of use while it actually increased the risk of switching during the first $11-15$ months after beginning use by $9.4 \%$. After 21 months of use, the IUD becomes more effective in reducing the chance of switching although not statistically significant.

The risk of switching among IUD users during all durations of use is a subject that needs great attention especially considering the shift in the method mix away from the IUD which is the most effective method available, the increased use of the IUD as a spacing method and that the switching is mainly to less effective methods (Khalifa et al., 2017). Also, the shift of the IUD users away from the public sector facilities for supplies and information can be indicative to women's reduced satisfaction of the service. In 2008 the DHS reported that $67 \%$ of the IUD users received their supplies and information from a public sector provider and that this share has dropped to $63 \%$ in 2014 (Ministry of Health and Population [Egypt], ElZanaty and Associates [Egypt] and ICF International, 2015a).

Controlling for all other variables, the results confirm that the woman's demographic characteristics such as age has a significant effect on the risk of switching to another method. This is consistent with previous findings (Ali and Cleland, 1999; Bradley et al., 2009; Steele and Curtis, 2003). Parity has a significant effect on the chances of switching and failure. This supports previous finding of (Bradley et al., 2009). On the other hand, this study does not fully support the argument made by researchers that socioeconomic variables are important in the case of switching and abandoning while in need. While Curtis and Blanc, 1997 has found that the risk of switching increases consistently with increasing education, we find this increase to take place only when the woman reaches a -relatively- high level of education and that it is not significantly related to the level of wealth index. In addition, women's education is positively related to abandonment while still in need, (although not 
JHASS 4,1

statistically significant) even though other studies confirmed a negative relationship (Curtis and Blanc, 1997). Interestingly, current study shows that woman's work is not a significant determinant of all three types of contraceptive discontinuation. Other studies have found increased intention to avoid pregnancies if women have the opportunity to work and therefore, be linked with decreases in rates of abandonment in need and failure, which would help women, couples and countries achieve their reproductive health goals (Bradley et al., 2009, p. 82).

The effect of media exposure was significant only as it decreased the chance of abandoning the method while in need. Increases in the community contraceptive prevalence rate slightly decreases the risk of abandoning the method significantly by $2.3 \%$ but significantly increases the chance of switching to another method by $1.5 \%$. This finding agrees with Bradley et al. (2009), who concluded that women's contraceptive use is related to norms in their communities.

However, recent changes in Egypt's vision are encouraging. In 2017 Egypt made a commitment to enhance family planning (Ministry of Health and Population [Egypt], UNPFA and USAID, 2017). The Government of Egypt pledges to:

Reduce unmet need for family planning (FP) from $12.6 \%$ in 2014 to $10.6 \%$ by 2020 , and the 12 month discontinuation rate from $29 \%$ in 2014 to $24 \%$ by 2020 and increase prevalence rate of all contraceptive methods used among married women (CPR) from $58.5 \%$ in 2014 to $62.8 \%$ by 2020 [FP2020, 2018].

Based on the findings of this research, it is suggested that although women are not wellinformed about contraceptive method effectiveness family planning counselling should be tailored to the most common reasons for discontinuation of each method separately. Abandonment while in need and switching are almost equally common among pill users while abandoning while in need is a very high risk among injectable users. The primary reason behind this behaviour for both pill and injectable users are health concerns and side effects. Switching would be the primary concern when counselling IUD users, as switching is basically to less effective methods. Programmatic interventions are challenged by the fact that most users discontinued so early in their contraceptive method without consulting a health care provider (Castle and Askew, 2015). Therefore, counselling should be more intense during the first year of method use and should pay special attention to women who are 25 years old and above and those who have two or more children. Media campaigns are important and especially those addressing the issue of abandoning while in need.

Results of this study confirm that the recent shift in the method mix away from the IUD to the hormonal methods which is accompanied by a shift from the public to the private sources, especially pharmacies are likely to have a negative impact on the discontinuation rates. It is a common practice that pills are provided across the counter by non-medical staff. Most Egyptian pharmacists lack basic information about family planning and counselling skills. Pharmacists did not receive any training in family planning, although some of the older pharmacists received training several years ago through the "Ask - Consult" network. Training of private pharmacists to provide counselling stopped in 2000.

Advocacy programmes should reach for women with three or more children, older women and secondary educated women who are more likely to switch to another method. Also, for women with three or more children lived in frontiers government who are more likely to have method failure.

Efforts to improve the existing monitoring and evaluation system are needed to provide accurate information regarding existing users, discontinuation and change of methods and 
unintended pregnancies, as well as activating the referral system at all levels. The results of EDHS 2014 showed that most of the Egyptian pill users obtain their supply from private pharmacies $63.1 \%$ (urban $76.1 \%$ - rural $56 \%$ ). This paper suggests that further research could highlight the gaps in the performance of the private sector. As a major provider of hormonal methods, it may have encouraged users to stop using. It is unfortunate that EDHS 2014 - unlike previous rounds - did not provide calendar data for discontinuation classified by the source of obtaining the method, and therefore a comparison between the users of the private and public sector was not possible. It is recommended that future rounds of the EDHS will provide such information.

\section{Note}

1. In Egypt family planning questions are directed only to married women.

\section{References}

Ali, M. and Cleland, J. (1995), "Contraceptive discontinuation in six developing countries: a causespecific analysis", International Family Planning Perspectives, Vol. 21 No. 3, pp. 92-97, doi: $10.2307 / 2133181$.

Ali, M. and Cleland, J. (1999), "Determinants of contraceptive discontinuation in six developing countries", Journal of Biosocial Science, Vol. 31 No. 3, pp. 343-360, doi: 10.1017/ S0021932099003430.

Arifin, E.N. (2003), "Factors associated with contraceptive discontinuation in Bali, Indonesia: a multilevel discrete-time competing risks hazard model", Asian MetaCentre for Population and Sustainable Development Analysis.

Austin, P.C. (2017), "A tutorial on multilevel survival analysis: methods, models and applications", International Statistical Review, Vol. 85 No. 2, pp. 185-203.

Blanc, A.K., Curtis, S.L. and Trevor, N.C. (2002), "Monitoring contraceptive continuation: links to fertility outcomes and quality of care", Studies in Family Planning, Vol. 33 No. 2, pp. 127-140, doi: 10.1111/j.1728-4465.2002.00127.x.

Bradley, S., Schwandt, H. and Khan, S. (2009), "Levels, trends and reasons for contraceptive discontinuation”, DHS Analytical Studies No. 20, ICF Macro, Calverton, MD.

Castle, S. and Askew, I. (2015), Contraceptive Discontinuation: Reasons, Challenges and Solutions, Population Council, New York, NY.

Curtis, S.L. and Hammerslough, C.R. (1995), "Model further analysis plan: contraceptive use dynamics", DHS Further Analysis Reports No. 59, Macro International, Calverton, MD.

Curtis, S.L. and Blanc, A.K. (1997), "Determinants of contraceptive failure, switching, and discontinuation: an analysis of DHS contraceptive histories", DHS Analytical reports No. 6. Macro International, Calverton, $\mathrm{MD}$.

El-Tawila, S. (1995), "Contraceptive use dynamics in Egypt", in Mahran, M. (Ed.) Perspectives on Fertility and Family Planning in Egypt, National Population Council (Arab Republic of Egypt), and Macro International, Calverton, $\mathrm{MD}$.

FP2020 (2018), "Egypt commitment self-reporting questionnaire 2018", available at: www. familyplanning2020.org/sites/default/files/Egypt-Commitment-Self-reporting-Questionnaire2018.pdf (accessed 3 June 2020).

Ferguson, A.G. (1992), "Fertility and contraceptive adoption and discontinuation in rural Kenya", Studies in Family Planning, Vol. 23 No. 4, pp. 257-267, doi: 10.2307/1966887.

Hox, J.J. (1995), Applied Multilevel Analysis, TT-publikaties. 


\section{JHASS 4,1}

ICF (2019), "The DHS program STATcompiler", Funded by USAID, available at: www.statcompiler. com (accessed 22 March 2019).

Jain, A. (1989), "Fertility reduction and the quality of family planning services", Studies in Family Planning, Vol. 20 No. 1, pp. 1-16, doi: 10.2307/1966656.

Jain, A. and Winfrey, W. (2017), "Contribution of contraceptive discontinuation to unintended births in 36 developing countries", Studies in Family Planning, Vol. 48 No. 3, pp. 269-277, doi: 10.1111/ sifp.12023.

Khalifa, M., Aziz, A.W. and Sakr, E. (2017), "Changes in contraceptive use dynamics in Egypt: analysis of the 2008 and 2014 demographic and health surveys", DHS Working Papers No.132. ICF, Rockville, MD.

Khalifa, M., Aziz, A.W., Metwally, S. and Sakr, E. (2020a), "The recent increase in contraceptive discontinuation in Egypt", Journal of Biosocial Science, Vol. 52 No. 1, pp. 154-157, doi: 10.1017/ S002193201900026.

Khalifa, M., Aziz, A.W. and Metwally, S. (2020b), "Contraceptive discontinuation in Egypt as fertility returns to its 2000 level", Journal of Humanities and Applied Social Sciences, Vol. 2 No. 1, pp. 19-32, doi: 10.1108/JHASS-09-2019-0056.

Ministry of Health and Population [Egypt], El-Zanaty and Associates [Egypt] and ICF International (2015a), Egypt Demographic and Health Survey 2014, Cairo, Egypt and Rockville, MD.

Ministry of Health and Population [Egypt], El-Zanaty and Associates [Egypt] and ICF International (2015b), Egypt Health Issues Survey 2015, Cairo, Egypt and Rockville, MD.

Ministry of Health and Population [Egypt], UNPFA and USAID (2017), "Egypt's commitment to enhance family planning with FP2020 global", available at: www.familyplanning2020.org/sites/ default/files/2017-Egypt-FP2020-Commitment.pdf (accessed 3 June 2020).

National Population Council (2015), National Strategic Population Plan 2015-2030, Cairo, Egypt.

Rabe-Hesketh, S. and Skrondal, A. (2012), Multilevel and Longitudinal Modeling Using Stata: Categorical Responses, Counts, and Survival, 3rd ed., Stata Press, Vol. 2.

Social Research Center (2011), "Fertility plateau in Egypt: a qualitative study", This study was done under the project "Policies to address fertility plateau in Egypt" coordinated by the Social Research Center (SRC) of the American University in Cairo (AUC) and supported by the UN Population Fund (UNFPA), Cairo Office.

StataCorp (2015), Stata: Release 14. Statistical Software, StataCorp LP, College Station, TX.

Steele, F. (2011), "Multilevel discrete-time event history models with applications to the analysis of recurrent employment transitions", Australian and New Zealand Journal of Statistics, Vol. 53 No. 1, pp. 1-20, doi: 10.1111/j.1467-842X.2011.00604.x.

Steele, F. and Curtis, S. (2003), "Appropriate methods for analyzing the effect of method choice on contraceptive discontinuation”, Demography, Vol. 40 No. 1, pp. 1-22, doi: 10.1353/dem.2003.0009.

Steele, F., Diamond, I. and Wang, D. (1996), "The determinants of the duration of contraceptive use in china: a multilevel multinomial discrete-hazards modeling approach”, Demography, Vol. 33 No. 1, pp. 12-23, doi: 10.2307/2061710.

\section{Corresponding author}

Mona Khalifa can be contacted at: monakhalifa2010@gmail.com

For instructions on how to order reprints of this article, please visit our website:

www.emeraldgrouppublishing.com/licensing/reprints.htm

Or contact us for further details: permissions@emeraldinsight.com 